\title{
DISCURSOS DESUMANIZANTES E VIOLAÇÃO SELETIVA DE DIREITOS HUMANOS SOB A LÓGICA DA COLONIALIDADE
}

\section{Fernanda Frizzo Bragato ${ }^{1}$}

\section{Resumo}

O objetivo deste estudo é analisar a relação existente entre a lógica da colonialidade, os discursos de desumanização que graduam os seres humanos em diferentes escalas de valor e a violação seletiva de direitos humanos por meio da discriminação. O estudo é resultado de investigações de cunho exploratório realizadas por meio de revisão bibliográfica teoricamente orientadas pelo referencial descolonial. Pretende investigar de que forma a violação de direitos humanos é seletiva e como o Direito Internacional dos Direitos Humanos atua em face da discriminação contra aqueles a quem se nega o pleno status de ser humano. Com base nisso, seu principal resultado consiste em afirmar que a proteção efetiva dos direitos humanos está ligada à condição daqueles sujeitos nos quais o discurso racional-individualista identifica os traços do humano enquanto a sua violação está ligada aos processos de discriminação sofridos por aqueles que não são percebidos como integralmente humanos. Este processo de privação de direitos resulta de uma lógica de colonialidade moderna e global que consiste na dominação por meio de discursos desumanizantes.

Palavras-chave: direitos humanos; colonialidade; discriminação

\section{INTRODUÇÃO}

Este artigo pretende problematizar a seguinte questão: existe uma relação entre (1) a depreciação de certos seres humanos que não são considerados plenamente humanos, (2) a violação seletiva de direitos humanos por meio da discriminação e (3) a lógica da colonialidade, que propõe algumas explicações para a ligação entre os dois fenômenos anteriores.

O Direito Internacional dos Direitos Humanos têm se expressado por meio de um corpo normativo que objetiva reverter os processos históricos de privação e de ofensa à dignidade da maioria dos seres humanos, reforçados por um discurso de relativização da sua humanidade que torna natural uma diferença hierárquica entre seres da mesma espécie. A inferioridade dos negros, índios, mulheres, homossexuais, não-cristãos e outros tem sido determinada por um discurso de gradação e hierarquia da humanidade, que sobrevive até hoje. A fim de justificar que alguns seres humanos não têm direitos e, portanto, podem ser discriminados foi anteriormente

\footnotetext{
${ }^{1}$ Pós-doutorado - Birkbeck College da Universidade de Londres; Professora de Direitos Humanos na Graduação e no Programa de Pós-graduação em Direito da UNISINOS. Coordenadora do Núcleo de Direitos Humanos da UNISINOS. E-mail: fernandabragato@yahoo.com.br
} 
necessário desconsiderá-los como plenos seres humanos. Por outro lado, a colonialidade é uma categoria cunhada por Aníbal Quijano que designa o lado obscuro da modernidade marcada pelas experiências do colonialismo. A forma como o poder é apropriado e exercido ainda segue a lógica do padrão colonial estabelecido na modernidade, mais precisamente desde a conquista da América pelos ibéricos. A modernidade foi a idade da hegemonia europeia sobre o resto do mundo à custa de relações de poder advindas do controle das formas de produção econômica (trabalho e recursos naturais), de construção do conhecimento (ciência como única forma legítima de saber) e da essencialização e hierarquização das identidades subjetivas (raça e gênero como elementos centrais de negação de humanidade). O fato de continuarmos a viver sob a égide da matriz colonial de poder denota que embora o colonialismo tenha praticamente chegado ao fim, é a colonialidade que marca as relações assimétricas de poder contemporâneas e, portanto, é uma categoria utilizada neste estudo para compreender os processos de violação seletiva de direitos humanos.

Primeiramente, discutir-se-á a dimensão discursiva da desumanização explorando como a construção ocidental da idéia de ser humano tornou possível a exclusão da maior parte deles do conceito de humanidade. Em segundo lugar, argumentar-se-á que as práticas e discursos de desumanização discriminatórios não só são interligados, mas também expressam a lógica da colonialidade. Finalmente, deve-se demonstrar que, em matéria de não-discriminação, o direito internacional dos direitos humanos assume o pressuposto de que a maioria das violações são estritamente ligadas à questão de quem são os titulares de direitos. Os fatores de discriminação estabelecidos e proibidos derivam de diferentes identidades classificadas de acordo com um padrão de humanidade discursivamente construído.

Este estudo é resultado das investigações de cunho exploratório realizadas por meio de análise e revisão bibliográfica teoricamente orientadas pelo referencial descolonial ${ }^{2}$.

\section{OS HUMANOS E OS IRRACIONAIS}

Certos seres humanos não são considerados plenamente humanos, devido a processos de desumanização em nível discursivo e prático a que são submetidos. Ou seja, há discursos de depreciação de certos seres humanos e práticas de discriminação que se sustentam nos primeiros. Tais práticas de discriminação respondem e explicam, em grande parte, a sistemática e ao mesmo tempo seletiva violação de direitos humanos que se iniciou na modernidade, mais precisamente a partir da conquista da América ${ }^{3}$, e que persiste até hoje. Por

\footnotetext{
${ }^{2} \mathrm{O}$ estudo faz parte das investigações parciais que se desenvolvem no âmbito do projeto de pesquisa "Teoria e história dos direitos humanos sob a perspectiva dos estudos descoloniais", devidamente cadastrado no Programa de Pós-Gradução de Direito da Unisinos.

${ }^{3}$ Neste artigo, adoto a posição de Dussel segundo a qual o projeto colonial que teve início com a conquista da América em 1492 representa a data de nascimento da modernidade, na medida em que permitiu à Europa afirmar sua centralidade planetária a partir da constituição dos espaços e dos povos periféricos (Dussel, 1993).
} 
outro lado, foi na modernidade que algumas lutas políticas resultaram nos primeiros reconhecimentos legais dos chamados direitos do homem. Esse reconhecimento foi sustentado por um discurso filosófico que estabeleceu dois dogmas do pensamento político moderno. Primeiro: todo homem tem direitos inalienáveis que decorrem de sua natureza humana; segundo: a racionalidade é o que nos distingue e nos define como humanos. Ao mesmo tempo em que a Europa reconhecia ao homem certos direitos inatos, violava estes mesmos direitos fora de suas terras, com o extermínio, escravização e os maus-tratos de indígenas americanos e de negros africanos. Apesar disso, não havia uma clara contradição entre a garantia dos direitos do homem e as práticas cruéis do além-mar. $\mathrm{O}$ discurso dos direitos foi construído sobre um arquétipo de sujeito de direitos que, todavia, não contemplava todos os seres humanos. Homens e mulheres negros e indígenas não eram plenamente humanos, portanto, que dignidade deveria ser respeitada? Todavia, como Douzinas (2000, p. 184) questiona, nós podemos ter um conceito de direitos humanos sem ter uma definição de quem ou o que é um humano?

Segundo Fairclough (2001), o discurso tem o poder construtivo tríplice: produz e reproduz conhecimentos e crenças por meio de diferentes modos de representar a realidade; estabelece relações sociais; cria, reforça ou reconstitui identidades. Nesse sentido, o discurso dos direitos do homem da modernidade permitiu que os direitos fossem garantidos à pequena parte da humanidade, enquanto o resto pôde deles ser destituída. Isso ocorre por meio da paulatina construção do conceito de humanidade a partir da racionalidade, que determinou quem contava e quem não contava como ser humano. Graças a este processo discursivo, o "homem" tornou-se o sujeito de direitos por excelência porque ele é racional e, portanto, possui uma dignidade. Como consequência, merece ser tratado como um fim em si mesmo e nunca simplesmente como meio. E porque todos os homens são igualmente racionais, todos são iguais e, assim, os direitos tornaram-se "naturais" para quem é humano.

Ser racional tem a ver com a capacidade de compreensão, raciocínio e linguagem de acordo com padrões científicos. Racionalidade apela para a máxima consistência com um princípio ou "razão" para a ação ou pensamento, de modo que ser inconsistente é uma questão de contradição. O surgimento da ciência moderna como a suprema regência epistêmica representou a promessa da expansão da racionalidade e, portanto, da segurança em questões de conhecimento (Gordon, 2010). Razão moderna é razão instrumental. De acordo com Fuchs,

Pessoas racionais são agentes autônomos que portam direitos subjetivos e inclinações particulares. Eles agem racionalmente numa variedade de áreas. $\mathrm{O}$ ator cognitivo cartesiano chega a indubitáveis obviedades lógicas e certezas por raciocínio sistemático. $\mathrm{O}$ ator moral kantiano segue princípios morais generalizáveis. $\mathrm{O}$ ator político hobbesiano pactua com outros atores a criação de um órgão de soberania política. $\mathrm{O}$ ator econômico de Smith investe seus recursos de forma prudente para maximizar os ganhos egoístas; a longo prazo, 
isso fará com que a comunidade também prospere. (Fuchs, 2001, p. 113)

Refletindo no final do século XVIII sobre a suposta inferioridade da mulher, Wollstonecraft (2000) questiona "em que é que a preeminência do homem sobre a criação bruta consiste? A resposta é tão clara como que uma metade é menor do que o todo: na razão. Que aptidão exalta um ser sobre o outro? Virtude; nós respondemos de forma espontânea”. Depois de responder claramente à sua própria pergunta, Wollstonecraft conclui que, embora sua resposta transpareça certa universalidade, as mulheres encontravam-se colocadas em uma posição inferior em relação aos homens, o que, para a autora, significava duas coisas: a razão obscurecida por preconceitos irracionais e, consequentemente, uma clara contradição no próprio discurso que definia o humano. No entanto, as causas do fenômeno segundo o qual as mulheres puderam ser excluídas do espectro da racionalidade, que afinal define quem conta como pleno ser humano, estava nas características comumente atribuídas ao sexo feminino, como a loucura, caprichos, paixões ardentes, vícios servis, graça e atratividade. Segundo a autora, todas essas características foram atribuídas às mulheres como um fato evidente e explicavam por que puderam ser vistas como seres infantis, instáveis e, portanto, incapazes de ter racionalidade e autonomia.

Embora pretensamente universal e abstrato, o conceito moderno de racionalidade é restrito aos padrões definidos pelo homem europeu em oposição a formas diferentes de pensar, julgar e comportar-se. Há pouco falei que o discurso de inferiorização teve seu ponto de partida na conquista da América. Como observa Dussel (1996, p. 9), a pergunta que, desde o princípio, interessou ao colonizador foi: “'Son hombres los indios?, es decir, ison europeos y por ello animales racionales? [...] son sólo la mano de obra, si no irracionales, al menos "bestiales", incultos - porque no tienen la cultura del centro-, salvajes... subdesarrollados".

Ginés de Sepulveda, teórico oficial da coroa espanhola, em debate do início do século XVI com Bartolomé de Las Casas a respeito da condição humana dos povos indígenas da América expressou a seguinte tese:

A esta lei estão submetidos os homens e os animais. Por isso, as feras se amansam e sujeitam-
se ao império do homem. Por isso, o varão impera sobre a mulher, o homem adulto sobre a
criança, o pai sobre os filhos, quer dizer, os mais poderosos e mais perfeitos sobre os mais
débeis e imperfeitos. Isso mesmo se verifica entre os homens; alguns, por natureza, são
senhores, outros, por natureza, são servos. Os que excedem em prudência e em gênio aos
demais, ainda que não em força corporal, são por natureza senhores; pelo contrário, os
tardios e preguiçosos de entendimento, mesmo que tenham forças corporais para cumprir
todas as obrigaçóes necessárias, são por natureza servos e é justo que o sejam, pois está
sancionado pela lei divina. Porque está escrito no livro dos Provérbios: aquele que é néscio
servirá ao sábio. Tais são as gentes bárbaras e inumanas, alheias à vida civil e aos costumes
paćíficos. E será sempre justo e conforme ao direito natural que tais gentes se submetam ao
império dos príncipes e nações mais cultas e humanas, para que, sob suas leis e suas virtudes,

\footnotetext{
${ }^{4}$ Rational persons are autonomous agents carrying subjective rights and private inclinations. They act rationally in a variety of areas. The Cartesian cognitive actor arrives at indubitable logical truisms and certainties by systematic reasoning. The Kantian moral actor follows generalizable moral principles. The Hobbesian political actor contracts with other actors to create a sovereign body politic. The Smithsian economic actor invests his resources prudently to maximize selfish gains; in the long run, this will make the commonwealth prosper as well.
} 
deponham a barbárie e se reduzam à vida mais humana e ao culto da virtude (Sepulveda, 1941, p. 85)

A dúvida sobre a natureza humana dos índios deu ao colonizador a certeza sobre sua própria humanidade-racionalidade. Ou como diz Dussel (1996, p.9), "antes que el ego cogito hay un ego conquiro (el "yo conquisto" es el fundamento práctico del "yo pienso")". Neste sentido, Maldonado-Torres observa que o:

"pienso, luego soy" tiene al menos dos dimensiones insospechadas. Debajo del "yo pienso" podríamos leer "otros no piensan", en el interior de "soy" podemos ubicar la justificación filosófica para la idea de que "otros no son" o están desprovistos de ser. De esta forma descubrimos una complejidad no reconocida de la formulación cartesiana: del "yo pienso, luego soy” somos llevados a la noción más compleja, pero a la vez más precisa, histórica y filosóficamente: "Yo pienso (otros no piensan o no piensan adecuadamente), luego soy (otros no son, están desprovistos de ser, no deben existir o son dispensables)". La formulación cartesiana privilegia a la epistemología, que simultaneamente esconde, no sólo la pregunta sobre el ser (el "soy") sino también la colonialidad del conocimiento (otros no piensan). El privilegio del conocimiento en la modernidad y la negación de facultades cognitivas en los sujetos racializados ofrecen la base para la negación ontológica. En el contexto de un paradigma que privilegia el conocimiento, la descalificación epistémica se convierte en un instrumento privilegiado de la negación ontológica o de la sub-alterización. "Otros no piensan, luego no son". No pensar se convierte en señal de no ser en la modernidad. (Maldonado-Torres, 2007, p. 144).

A racionalidade, que define o ser, está no nível do conhecimento, ao passo que a negação de faculdades cognitivas - seja nos sujeitos colonializados, seja na mulher - oferecem a base para a negação de sua humanidade. Ou seja: quem não pensa, não é. Em relação aos povos indígenas, não importa se pensavam de acordo com sua cosmovisão, já que esta não era uma forma legítima de pensar. Observa Smith (2008, p. 74) que os conceitos indígenas de espiritualidade indicam formas contrastantes com a perspectiva ocidental de compreender o mundo. Trata-se de uma cosmovisão que não concebe a pessoa humana isolada de uma genealogia que pode ser rastreada até a Mãe Terra e que implica uma relação compartilhada com outros seres animados e, no sentido ocidental, inanimados. Rochas e insetos, por exemplo, mantêm com as pessoas um espaço compartilhado pleno de sentido, o que é extremamente difícil para os sistemas ocidentais de conhecimento lidarem ou aceitarem.

Precisamente porque se opõem aos padrões racionais europeus, formas e visões alternativas de ser e de se relacionar com o mundo foram suficientes para caracterizar determinados grupos humanos como bárbaros, selvagens e brutos. Ao invés de direitos, passaram a se impor repressão, negação e contenção disciplinar. Tudo isso se tornou possível porque, segundo Mignolo (2013, p. 46), a idéia do ser humano e de direitos foi inventada pelos humanistas do Renascimento europeu para responder, por um lado, à história interna dos cristãos do Ocidente e, por outro lado, a uma história externa do cristianismo. Internamente, o conceito de homem serviu para distinguir humanistas de orientais e pagãos; externamente eles aplicaram os mesmos conceitos para afirmar a sua própria humanidade antes de atribuírem o nome de índios e negros às populações do Novo Mundo. Mignolo vai mais longe para refletir sobre a origem do discurso da superioridade ocidental através da definição de homem e humano. A sua reflexão é digna de uma longa citação: 
Homem e humano - e não sangue ou cor da pele - é a linha inferior da classificação racial. E classificação racial não é nada mais do que uma resposta para a pergunta "quem fala pelo ser humano? "Raças classificadas não existem no mundo, mas no universo discursivo da teologia, filosofia e ciência ocidentais. Como a classificação racial existente — desde o Renascimento - pressupõe um ranking dos seres humanos, dependendo de sua aproximação aos princípios do conhecimento - crença e racionalidade, forma de vida e organização sócio-econômica - e na aproximação ontológica com o Homem Vitruviano - forma e usos sociais do corpo, tais como postura, caminhada, dança e rituais cristãos e não-cristãos - , os atores que desempenham e mantêm a classificação racial são os que falam pelo ser humano. (Mignolo, 2013, p. 51)

Por isso, segundo Mignolo, "o conceito de humano utilizado em conversas, nos meios de comunicação, em seminários universitários e conferências, é um conceito que deixa fora da "humanidade” grande parcela da população mundial” (Mignolo, 2013, p. 44). As pessoas cujos etnia, cor da pele, língua, rotinas e rituais são "humanamente" deficientes compõem esta grande parcela. No mesmo sentido, Sánchez Rubio aponta que a idéia dos direitos humanos está embutida em um imaginário excessivamente eurocêntrico e linear que acaba por estabelecer uma cultura extremamente entorpecida que se limita a uma forma hegemônica e única do ser humano: aquela construída pela trajetória ocidental e pela versão da modernidade liberal burguesa (Sánchez Rubio, 2014, p. 49).

Direitos humanos assumem uma ideia de que seu sujeito é o ser humano que se define como ser racional. O problema disso é que embora alguns seres pareçam humanos, eles não são considerados plenamente racionais e, portanto, não se credenciam como sujeitos plenos de direitos humanos.

\section{O DISCURSO DESUMANIZANTE E A LÓGICA DA COLONIALIDADE}

Nesta seção, discutir-se-á a lógica colonial da privação de direitos a partir de duas premissas discutidas anteriormente. A primeira delas é a existência de um discurso que define humanidade e, ao mesmo tempo, exclui desta categoria a maioria dos seres humanos, criando hierarquias que coloca as mulheres índias e negras nos níveis mais baixos e o homem branco nos níveis superiores. A segunda é que este discurso e as práticas subseqüentes de violações começaram no alvorecer da modernidade e permanecem até hoje. O conceito de modernidade assumido neste estudo é o de Quijano (2005): concepção eurocêntrica segundo a qual a modernidade é um fenômeno meramente intraeuropeu, portanto, imaginado como experiência e produto exclusivamente europeus. À modernidade são associadas ideias de avanço, novidade, laico-secular, racionalização e ciência em relação às

\footnotetext{
${ }^{5}$ Man and human — and not blood of skin color-is the bottom line of racial classification. And racial classification is nothing more than one answer to the question "who speaks for the human?". Classified races do not exist in the world but in the discursive universe of Western theology, philosophy and science. As existing racial classification — since the Renaissance - presupposes a ranking of human beings depending on their approximation to principles of knowledge—belief and rationality, form of life and socioeconomic organization - and on ontological approximation to the Vitruvian Man-form and social uses of the body such as posture, walking, dance, rituals, and Christian and non-Christian rituals-the actors who perform and maintain racial classification are the ones who speak for the human.
} 
quais os europeus reivindicaram a autoria e o protagonismo exclusivos. A concomitante emergência do primeiro sistema-mundo global historicamente conhecido, a partir de uma comum dominação colonial/imperial iniciada com a conquista da América, alçou a Europa à posição de centro enquanto o resto do mundo tornou-se sua periferia. Os povos colonizados e suas respectivas histórias e culturas foram situados no passado de uma trajetória histórica cuja culminação era Europa. As relações entre Europa metropolitana e suas colônias foram codificadas na seguinte perspectiva binária: Oriente-Ocidente, primitivo-civilizado, mágico/mítico-científico, irracionalracional, tradicional-moderno. O sistema-mundo colonial-moderno abarcou toda a humanidade atual e implicou o controle de cada um dos âmbitos da existência social por instituições organizadas de forma sistêmica e interdependente. $\mathrm{O}$ trabalho, seus recursos e seus produtos são controlados pela empresa capitalista, o sexo pela família burguesa, a autoridade pelo Estado-Nação e a intersubjetividade pelo eurocentrismo (Quijano, 2005).

No entanto, colonialidade - outro conceito-chave deste estudo - não é o mesmo que colonialismo. Como Maldonado-Torres (2007, p. 243) explica, "o colonialismo denota uma relação política e econômica em que a soberania de uma nação ou de um povo repousa sobre o poder de outra nação, o que torna essa nação um império". E este foi um processo eminentemente moderno, que tornou possível a emergência do sistema-mundo global. Por outro lado, "colonialidade refere-se a padrões de poder de longa data que surgiram como resultado do colonialismo, mas que definem a cultura, o trabalho, as relações intersubjetivas e a produção de conhecimento muito além dos limites rígidos das administrações coloniais". Assim, mesmo que o colonialismo tenha praticamente chegado ao fim, a colonialidade sobrevive a ele. De acordo com Grosfoguel (2008):

Continuamos a viver sob a mesma "matriz de poder colonial". Com a descolonização jurídico-política saímos de um período de "colonialismo global" para entrar num período de "colonialidade global". Embora as "administrações coloniais" tenham sido quase todas erradicadas e grande parte da periferia se tenha organizado politicamente em Estados independentes, os povos não-europeus continuam a viver sob a rude exploração e dominação europeia/euro americana. As antigas hierarquias coloniais, agrupadas na relação europeias versus nãoeuropeias, continuam arraigadas e enredadas na "divisão internacional do trabalho" e na acumulação do capital à escala mundial.

Colonialidade é a marca das relações de poder entre metrópoles e colônias desde o início da modernidade colonial e significa que estas relações são desiguais e se estabelecem mediante processos de exploração baseados em dois pressupostos. Segundo Quijano (2005, p. 227), a matriz colonial de poder define-se, de um lado, a partir da "codificação das diferenças entre conquistadores e conquistados na idéia de 'raça', uma estrutura biológica supostamente diferente que colocou alguns em uma situação natural de inferioridade em relação aos outros". Esta ideia foi assumida pelos conquistadores como uma premissa básica de suas relações com os nativos americanos. De outro lado, colonialidade define-se pela "constituição de uma nova estrutura de controle do trabalho e dos seus recursos, da escravidão, da servidão, da pequena produção mercantil independente, em conjunto e sobre a base do capital e do mercado mundial" (Quijano, 2005, p. 227).

Este padrão de poder não ficou adstrito apenas ao projeto colonizatório da América. Maldonado-Torres 
(2007, p. 244) aponta que ele se tornou a base da identidade moderna no quadro do capitalismo mundial e de um sistema de dominação estruturado em torno da idéia de raça, de modo que "este modelo de poder está no coração da experiência moderna”. Mignolo (2008, p. Xiii) acrescenta que "A 'descoberta' da América e o genocídio dos índios e dos escravos africanos são o próprio fundamento da modernidade, mais do que as revoluções francesa ou industriais". Por conta disso, a colonialidade é a face oculta e mais obscura da Modernidade.

A relação entre colonialidade e a depreciação de certos seres humanos encontra-se claramente estabelecida em Anibal Quijano que a situa nas primeiras discussões sobre se os índios tinham ou não alma. Novas identidades e um novo tipo de classificação social foram criados no contexto da colonização europeia. Como algumas identidades foram consideradas superiores em relação a outras, as relações entre os sujeitos foram consequentemente verticalizadas. Para ser possível pensar em tal hierarquização, a humanidade teve que ser graduada (Maldonado-Torres, 2007, p. 244). De acordo com Quijano:

As relações sociais fundadas na categoria de raça produziram novas identidades sociais e históricas na América - índios, negros e mestiços - e redefiniram outros. Termos como Espanhol e Português e, muito mais tarde, Europeu, que até então indicava apenas origem geográfica ou país de origem, a partir de então adquiriram uma conotação racial em referência às novas identidades. Na medida em que as relações sociais que estavam sendo configuradas eram relações de dominação, tais identidades foram constitutivas das hierarquias, lugares e papéis sociais correspondentes, e, consequentemente, do modelo de dominação colonial que estava sendo imposto. Em outras palavras, raça e identidade racial foram estabelecidas como instrumentos de classificação social básica. (Quijano, 2005, p. $228)^{6}$

Smith (2008, p.60) ressalta que houve, ainda, uma subclassificação social dos povos que foram racializados, de acordo com uma suposta capacidade de alcançar o arquétipo ideal de humanidade ligado às capacidades cognitivas-intelectuais mais próximas do padrão ditado pelo cânone científico. Mas é Ottobah Cugoano - um escravo liberto do século XVIII - que desvela o papel fundamental que o discurso da raça jogou na consolidação do sistema capitalista, de modo que nenhuma outra justificação poderia ser encontrada para a escravidão moderna que não os interesses econômicos:

$\mathrm{Na}$ história da humanidade, as várias depredações cometidas no mundo, por meio da escravização, extirpação e destruição dos homens foram sempre contrárias às leis de Deus, e o que ele segue estritamente proibido e ordenado que não seja feito. Mas homens insolentes, orgulhosos e ímpios, em todas as idades e em todos os lugares, são iguais; eles ignoram as leis do Altíssimo [...], de modo que eles podem tender a promover seu próprio lucro e ambição. Tais são todos os depredadores, sequestradores, mercadores e escravizadores dos homens;

\footnotetext{
${ }^{6}$ Social relations founded on the category of race produced new historical social identities in America - Indians, blacks, and mestizos - and redefined others. Terms such as Spanish and Portuguese and, much later, European, which had until then indicated only geographic orign or country of orign, acquired from then a racial connotation in reference to the new identities. Insofar as the social relations that were being configurated were relations of domination, such identities were constitutive of the hierarchies, places, and corresponding social roles, and consequently of the model of colonial domination that was being imposed. In other words, race and racial identity were established as instruments of basic social classification.
} 
eles não se importam, nem consideram o quanto ferem os outros, se podem trazer qualquer vantagem para si mesmos por ela (Cugoano, 1787). ${ }^{7}$

No que diz respeito à idéia de raça, Maldonado-Torres (2007, p. 244) aponta que o significado da categoria formal de raça produzido pela revolução biológica do século XIX não é o mesmo que o de 'raza' do século XVI. No entanto, o racismo científico do século XIX reproduz a mesma atitude dos colonizadores relativa às diferenças em graus de humanidade dos indivíduos colonizados e escravizados nas Américas e na África no século XVI. No mesmo sentido, Carneiro (2005) observa que as diferenças e as hierarquias raciais fomentaram o pensamento intolerante que vem sendo alimentado desde o século XV. Portanto, é um fenômeno moderno. O racismo tradicional - séc. XV-XVIII - propugnava o mito da pureza de sangue, transformando os cristãos-novos em párias e o mesmo valeu para indígenas, ciganos e negros. No século XIX, metamorfoseou-se no mito ariano, em que diferenças imutáveis de ordem física e intelectual, explicadas pela biologia e hereditariedade, predisposição para hábitos/comportamentos, degeneração biológica da raça através da miscigenação, constituíram-se em discursos de uma elite ilustrada com o objetivo de controlar e subjugar aqueles que eram considerados perigosos à fé católica, ao progresso da civilização ou à segurança nacional. Assim, contra os “inimigos” projetaram-se o ódio e a fobia.

Portanto, desde a modernidade e a projeção do Ocidente como centro do mundo, estabeleceu-se uma forma de exercício de poder de matriz colonial: inferiorizar, por meio do conceito de raça, para dominar em nome de interesses econômicos e políticos. Smith (2008, p. 64) explica esse processo, aduzindo que o nexo entre formas culturais de conhecer, descobertas científicas, impulsos econômicos e poder imperial permitiu ao Ocidente fazer reivindicações ideológicas sobre uma civilização superior. A “idéia” de Ocidente tornou-se realidade quando foi novamente reapresentada às nações indígenas por meio do colonialismo, que não só significou a imposição da autoridade ocidental sobre terras, modos de produção e leis indígenas, mas a imposição da sua autoridade sobre todos os aspectos dos saberes, línguas e culturas indígenas.

O discurso de matriz colonial que sustenta uma forma específica de poder sobreviveu aos dias de hoje porque as formas de produção de conhecimento hegemônico também são colonizadas e determinam os critérios sob os quais toda a experiência humana e social tem que ser avaliada. E este é o segundo eixo da colonialidade: a colonialidade do saber.

Lander (2005) aponta que a concepção do conhecimento ocidental pressupõe a existência de uma meta-narrativa universal que coloca todas as culturas e todos os povos dentro de um esquema que vem de um estágio primitivo e tradicional para o moderno. A História é entendida como um caminho evolutivo em direção

\footnotetext{
${ }^{7}$ In the history of mankind, the various depredations commited in the world, by enslaving, extirpating and destroying men, were always contrary to the laws of God, and what he head strictly forbidden and commanded not to be done. But insolente, proud, wicked men, in all ages, and in all places, are alike; they disregard the laws of the Most High, [...] so as it may tend to promote their own profit and ambition. Such are all the depredators, kidnappers, merchandisers and enslavers of men; they do not care, nor consider, how much they injure others, if they can make any advantage to themselves by it
} 
ao progresso que implica estágios mais e menos desenvolvidos e nos quais toda a humanidade está inexoravelmente incorporada. Europa - e de forma mais ampla, o Ocidente - tornaram-se tanto o vetor do processo evolutivo e a encarnação do estágio superior a ser perseguido. Isso porque a sociedade capitalista liberal é a expressão mais avançada desta perspectiva histórica e, portanto, define o modelo moderno de sociedade. Como um padrão universal, marca o único futuro possível de todas as outras culturas e povos, de modo que aqueles que não podem ser incorporados na marcha inexorável da história estão destinados a desaparecer (ou pelo extermínio ou pela assimilação).

As categorias, conceitos e perspectivas (economia, estado, sociedade civil, mercado, classes, etc.) tornaram-se não só categorias universais para a análise de qualquer realidade, mas também proposições normativas que definem a forma universal de ser e agir. Elas transmitem um tipo de conhecimento que compõe os padrões a partir dos quais se pode analisar e detectar deficiências, atrasos, freios e impactos que são o produto de caráter primitivo ou tradicional em todas as outras sociedades. Todo o tempo e espaço para a humanidade são concebidos e organizados a partir do ponto de vista da experiência ocidental, colocando a sua especificidade histórica e cultural como padrão superior e universal (Lander, 2005).

A lógica existente por trás das formas de produção e de adesão ao conhecimento é, por isso, chamada de eurocêntrica. A partir desta perspectiva, a Modernidade é o signo da superioridade europeia. Modernas concepções epistemológicas, antropológicas, políticas e históricas priorizam, respectivamente, as idéias de conhecimento científico, racionalismo, liberalismo e progresso. Eurocêntrica são aquelas concepções que afirmam a universalidade e a validade exclusiva desses modelos e ignoram outras formas de conhecimento, ou excluem a possibilidade de coexistência com outros tipos de conhecimento.

Para Smith (2008, p 68), o outro foi colonizado por disciplina: uma forma de organizar não só sistemas de conhecimento, mas também pessoas ou organismos. A disciplina trabalhou de diversas maneiras, mas "as formas mais óbvias [de disciplina] foram através de exclusão, marginalização e negação. Formas indígenas de saber foram excluídos e marginalizados". O que apoiou a disciplina foram "políticas e legislações paternalistas e racistas aceitas pelas comunidades brancas como condições necessárias que tinham de ser cumpridas caso os povos indígenas quisessem se tornar cidadãos (de suas próprias terras)”. Smith (2008, p. 69) continua argumentando que o "efeito de tal disciplina foi silenciar (para sempre em alguns casos) ou para suprimir as formas de conhecimento e os idiomas de muitos povos indígenas diferentes".

A colonialidade do saber indica a prevalência das formas de conhecimento ocidentais, ao passo que silencia e rebaixa as demais. Portanto, a colonialidade ajuda a entender a depreciação de certos seres humanos por meio de sua desumanização discursiva e prática. O discurso de gradação e inferiorização humana continua repercutindo porque ele afirma justamente aquilo que fomos ensinados a acreditar: que há povos superiores que falam dos e pelos outros e estabelecem o que são fraquezas, falhas e defeitos a serem repudiados. 


\section{VIOLAÇÃO DE DIREITOS HUMANOS E DISCRIMINAÇÃO}

Direitos humanos são sistematicamente violados em todas as partes do mundo, porém a violação não atinge a todos os indivíduos indistintamente, na medida em que há os que são mais vulneráveis à violação da dignidade que outros. De fato, os indivíduos não têm igual acesso a direitos universalmente proclamados. A sua proteção parece estar ligada à condição daqueles sujeitos nos quais o discurso racional-individualista identifica os traços do humano enquanto a sua violação parece estar ligada aos processos de discriminação sofrida por aqueles que não são percebidos como integralmente humanos.

Os discursos de inferiorização e depreciação de certos seres humanos, consolidados desde a Modernidade colonial, acarretam práticas de discriminação que se expressam em diferentes formas de violação de direitos humanos. Como Maldonado-Torres (2007) demonstra, a experiência vivida dos povos racializados é profundamente tocada pelo encontro constante com a violência e a morte, porque em um mundo estruturado com base na falta de reconhecimento da maior parte da humanidade, a idéia de raça sugere não só inferioridade, mas também dispensabilidade. Assim, a pobreza, a proximidade da morte na miséria, a falta de reconhecimento, o linchamento e a prisão são formas, dentre tantas outras, de caracterizar a situação do damné.

A violação seletiva de direitos humanos tem relação direta com a negação ou com o rebaixamento da humanidade de alguém. Inicialmente, pode parecer que a lógica de negação ou gradação da humanidade cessou com o fim do colonialismo, já que a escravidão foi abolida, ainda que o massacre dos índios continue bastante evidente no século XXI. Todavia, a noção de colonialidade serve para mostrar que, embora o colonialismo tenha chegado ao fim, as suas consequências no modo de exercer poder e de construir saber ainda persistem. Os sujeitos a quem a modernidade negou a plena humanidade são os mesmos que, na contemporaneidade, ainda lutam por reconhecimento em sociedades marcadas pelo preconceito. Como observa Carneiro (2007), preconceito é um conjunto de atitudes que provocam, favorecem ou justificam medidas de discriminação. A autora complementa que a manifestação do preconceito contribui para manter as características de um determinado grupo, bem como sua posição privilegiada à custa dos participantes do grupo de comparação, que são julgados não pelos seus méritos mas por qualidades atribuídas com base em falsos argumentos. Dentre as formas mais importantes de preconceito, está o racismo, mas a ele se somam o machismo, a xenofobia, homofobia e outros.

O direito internacional dos direitos humanos vem construindo um arcabouço de normas voltado para o combate da discriminação e a garantia de direitos humanos justamete àqueles a quem se nega o pleno status de ser humano. De acordo com Buchanan:

O compromisso de afirmar e proteger o igual status moral básico é talvez mais explícito na inclusão de fortes direitos contra a discriminação em razão do sexo ou raça. Historicamente, a discriminação contra as mulheres e pessoas de cor geralmente tem sido justificada com apelos a crenças sobre supostas diferenças naturais, mas como marcas de inferioridade. Em particular, a discriminação foi justificada com o argumento de que as mulheres ou pessoas de vol.09, nº. 04, Rio de Janeiro, 2016. pp. 1806-1823 1816 
cor são naturalmente menos racionais do que os homens ou brancos, contra a suposição de fundo de que a racionalidade é um traço especialmente valioso que distingue os humanos dos chamados animais inferiores. Em tal contexto, caracterizando determinadas classes de seres humanos como menos racionais do que outros, por natureza, transmite-se uma mensagem de inferioridade, sugerindo que eles são, em certo sentido, menos do que totalmente humanos. (Buchanan, 2013, p. 91). ${ }^{8}$

A discriminação implica tratamentos desiguais que consistem na negação de direitos humanos básicos, com base em determinados traços identitários percebidos como inferiores. Estes critérios, reconhecidos como geradores de discriminação, foram basicamente aqueles que, no discurso filosófico moderno, serviram de justificação para a gradação da espécie humana em diferentes níveis, quais sejam cor, raça, sexo e gênero, e classe social. $\mathrm{O}$ artigo $2^{\circ}$ da Declaração Universal dos Direitos Humanos estabelece que "Todo ser humano tem capacidade para gozar os direitos e as liberdades estabelecidos nesta Declaração, sem distinção de qualquer espécie, seja de raça, cor, sexo, idioma, religião, opinião política ou de outra natureza, origem nacional ou social, riqueza, nascimento, ou qualquer outra condição”. Os mesmos motivos de discriminação são proibidos no artio 26 do Pacto Internacional de Direitos Civis e Políticos da ONU, assim como no artigo 2o do Pacto Internacional de Direitos Econômicos, Sociais e Culturais da ONU e no artigo $1^{\circ}$ da Convenção Americana de Direitos Humanos "Pacto de San Jose, Costa Rica”. Maldonado-Torres aponta que estas formas de diferenciação humana não apenas dividiram o mundo, mas são ligadas entre si:

Género, casta, raza y sexualidad son, quizás, las cuatro formas de diferenciación humana que han servido más frecuentemente como medios para transgredir la primacía de la relación entre yo y el Otro, y para obliterar las huellas de la dimensión trans-ontológica en el mundo civilizado concreto. Em la modernidad, la diferenciación racial altera la forma como funcionan las otras formas de diferenciación humana. La división racial en la geo-política del planeta altera todas las relaciones de dominación existentes. La idea de raza o, más bien, el escepticismo misantrópico maniqueo colonial, no es independiente de categorías de género y sexualidad, ya que la feminización y cierto tipo de erotismo son parte fundamental de la misma. He argumentado aquí que el entrecruzamiento entre raza, género y sexualidad puede ser explicado, aunque sea en parte, por su relación con la no-ética de la guerra y su naturalización en el mundo moderno/colonial. (Maldonado-Torres, 2007, p. 153)

A discriminação tem um conceito claramente estabelecido no Direito Internacional, mais especificamente nos seguintes documentos: Convenção Internacional sobre a Eliminação de Todas as Formas de Discriminação Racial da ONU; Convenção sobre a Eliminação de Todas as Formas de Discriminação contra a Mulher da ONU; Convenção sobre os Direitos da Pessoas com Incapacidade da ONU; Convenção n 111 da Organização Internacional do Trabalho (OIT); e Convenção da UNESCO relativa à luta contra as Discriminações no campo do Ensino. De acordo com estes documentos, discriminação significa

\footnotetext{
${ }^{8}$ The commitment to affirming and protecting equal basic moral status is perhaps most explicit in the inclusion of strong rights against discrimination on grounds of gender or race. Historically, discrimination against women and people of color has usually been justified by appeals to beliefs about supposed natural differences, but as marks of inferiority. In particular, discrimination has been justified on the grounds that women or people of color are naturally less rational than men or whites, against the background assumption that rationality is an especially valuable trait that distinguishes humans from so-called lower animals. In such a context, vol.09, nº. 04, Rio de Janeiro, 2016.pp. 1806-1823 1817
} 
"toda a distinção, exclusão ou restrição [baseada em ... ] e que tenha por objeto ou resultado prejudicar ou anular o reconhecimento, gozo ou exercício, em igualdade de condições, dos direitos humanos e liberdades fundamentais nos campos político, econômico, social, cultural e civil ou em qualquer outro campo".

A expressão "baseada em", de acordo com os documentos supramencionados, referem-se à raça, cor, descendência, origem nacional ou étnica, sexo, incapacidade, religião, opinião política, origem social, linguagem e nascimento. Isso significa que alguns indivíduos ou grupos podem sofrer distinção, exclusão ou restrição no exercício dos seus direitos simplesmente por causa da presença de um ou alguns destes traços identitários. Ao longo deste artigo, tem-se argumentado que o problema da violação dos direitos humanos está diretamente ligado com a definição do ser humano, que é o sujeito desses direitos: se alguns seres não são racionais e, portanto, não totalmente humanos, então os seus direitos podem ser negados. A categoria da colonialidade explica exatamente que sujeitos foram historicamente reputados irracionais e como foi possível a criação de um estereótipo de sujeito de direitos que se reflete na figura do homem branco, heterossexual, e cristão, de modo que quanto mais alguém se distancia deste modelo, mais vulnerável à violação dos seus direitos alguém se torna. Em duas passagens de "Pele negras, mascaras brancas", Fanon deixa isso muito claro:

O problema é saber se é possível ao negro superar seu sentimento de inferioridade, expulsar de sua vida o caráter compulsivo, tão semelhante:

Ao problema fóbico. No negro, existe uma exacerbação afetiva, uma raiva em se sentir
pequeno, uma incapacidade de qualquer comunhão que o confina em um isolamento
intolerável. (Fanon, 2008, p. 35)
Um branco, nas colônias, nunca se sentiu inferior a quem quer que seja. [...] O colonizador,
se bem que "em minoria", nunca se sente inferiorizado. [...] A inferiorização é o correlato
nativo da superiorização europeia. Precisamos ter a coragem de dizer: é o racista que cria o
inferiorizado. (Fanon, 2008, p. 68-69)

Portanto, discriminação ou tratamento desigual, de acordo com a lógica da colonialidade, atinge mulheres, indígenas, negros, deficientes, pessoas homossexuais. Trata-se do oprimido, de que fala Dussel (1996), do damné, de que fala Fanon: "El damné es el sujeto que emerge en el mundo, marcado por la colonialidad del ser. / ... / existe en la modalidad de no-estar-ahí; lo que apunta a la cercanía de la muerte o a su compañía”. (Maldonado-Torres, 2007, p. 151).

characterizing certain classes of humans as less rational than others by nature conveys a message of inferiority, even suggesting that they are, in a sense, less than fully human.

${ }^{9}$ We must see whether it is possible for the black man to overcome his feeling of insignificance, to rid his life of the compulsive quality that makes it so like the behavior of the phobic. Affect is exacerbated in the Negro, he is full of rage because he feels small, he suffers from an inadequacy in all human communication, and all these factors chain him with an unbearable insularity. (Fanon, 2008, p. 35)

A white man in a colony has never felt inferior in any respect. (...) The colonial, even though he is "in the minority," does not feel that this makes him inferior. [...] The feeling of inferiority of the colonized is the correlative to the European's feeling of superiority. Let us have the courage to say it outright: It is the racist who creates his inferior. (Fanon, 2008, p. 68-69). 
Discriminação, como um tratamento que induz a privações, opera tanto direta quanto indiretamente ${ }^{10}$. As duas modalidades de discriminação podem ser diretamente inferidas dos termos do seu conceito jurídico, partindo-se das expressões "propósito" e "efeito". Como explica Rios (2008, p. 21), a discriminação é qualificada seja pelo propósito com que a ação é praticada, seja pelo efeito que gera. Ela alcança não apenas práticas intencionais e conscientes (que é o caso da discriminação direta), mas realidades permanentes que se reproduzem e se reforçam ao longo do tempo por meio da manutenção de medidas aparentemente neutras, mas efetivamente discriminatórias (que é o caso da discriminação indireta). No último caso, medidas (leis, políticas públicas etc) aparentemente neutras e não direcionadas a nenhum grupo específico acabam por reforçar as situções de vantagem e desvantagem já existentes na sociedade e que são ligadas a diversos fatores, como raça e sexo, por exemplo.

Até recentemente, era comum que o tratamento discriminatório fosse não apenas explícito, mas também legalmente previsto, como no caso dos sistemas de apartheid justificadas sob a suposta necessidade de segregar com base na cor. Este tipo de discriminação começou a ser questionada e posta em causa pelos movimentos por direitos civis e as lutas anti-descolonização de meados do século XX. Na memorável "Carta de uma Prisão em Birmingham", escrita em 1963 pelo líder do movimento dos direitos civis nos EUA, Martin Luther King, Jr., ele não só acusa as leis de segregação de danos a personalidade, mas também identifica a razão pela qual estes estatutos eram resolutamente dispostos a isso. As leis de segregação criam, ao mesmo tempo, a falsa sensação de superioridade ao segregador e a falsa sensação de inferioridade ao segregado, permitindo que atrocidades como as que o autor claramente descreve na seguinte citação sejam toleradas:

Mas quando você viu bandos perversos lincharem suas mães e pais à vontade e afogar suas irmãs e irmão a seu capricho; quando você viu policiais cheios de ódio amaldiçoarem, chutarem e até matarem seus irmãos e irmãs negros; quando você vê a vasta maioria de seus vinte milhões de irmãos negros sufocando-se em uma jaula hermética da pobreza em meio a uma sociedade de abundância; quando você de repente descobre sua língua travada e sua fala gaga ao tentar explicar a sua irmã de seis anos de idade por que ela não pode ir ao parque de diversões público cuja propaganda acabou de passar na televisão, e vê lágrimas jorrando dos olhos dela quando the é dito que o Funtown está fechado para crianças de cor, e vê ameaçadoras nuvens de inferioridade começando a se formar no pequeno céu mental dela, $\mathrm{e}$ a vê começar a distorcer sua personalidade ao desenvolver um rancor inconsciente contra as pessoas brancas; quando você tem de inventar uma resposta a um filho de cinco anos de idade que está perguntando: "papai, por que as pessoas brancas tratam as pessoas de cor tão mal?"; quando você faz uma viagem através de seu estado e descobre ser necessário dormir noite após noite nos cantos desconfortáveis de seu carro porque nenhum motel o aceita; quando você é humilhado entra dia sai dia por sinais irritantes dizendo "branco" e "de cor"; quando seu prenome tornasse "neguinho", seu nome do meio tornasse "menino" (não importa sua idade) e seu sobrenome tornasse "John", e sua mulher e mãe nunca são chamadas pelo título respeitável de "Sras."; quando você é perseguido de dia e assombrado à noite pelo fato de que você é um negro, vivendo constantemente na ponta dos pés, sem

\footnotetext{
${ }^{10}$ A distinção pode ser encontrada em Rios (2008, p. 22), inspirado nas seguintes figuras do direito norteamericano: disparate treatment para se referir à discriminação direta e disparate impact, para se referir à discriminação indireta.
} 
saber exatamente o que esperar em seguida, e é atormentado por medos interiores e ressentimentos exteriores; quando você está sempre lutando contra uma impressão degradante de "não ser ninguém" - então você entenderá porque achamos difícil esperar. Chega um momento em que a capacidade de suportar esgotasse, e os homens não estão mais dispostos a mergulhar no abismo do desespero. (King Jr, 1963).

Mesmo que os tratamentos discriminatórios diretos já não sejam tão comuns como a alguns anos atrás, o estigma de inferioridade de certos grupos persiste juntamente com os discursos que lhes dão suporte, mantendo vivos os tratamentos que negam o status de igualdade. No recente relatório produzido após a sua visita ao Brasil, o Grupo de Trabalho de Peritos sobre Pessoas de Ascendência Africana (ONU, 2014) reportou que a discriminação no país é disfarçado e crescente ${ }^{11}$.

No domínio da igualdade e não-discriminação, a Corte Interamericana de Direitos Humanos declarou no caso "Atala Riffo e filhas v Chile" que a igualdade não é compatível com tratamento privilegiado de acordo com a superioridade percebida de alguns grupos em detrimento de outros:

Sobre el principio de igualdad ante la ley y la no discriminación, la Corte ha señalado, la noción de igualdad se desprende directamente de la unidad de naturaleza del género humano y es inseparable de la dignidad esencial de la persona, frente a la cual es incompatible toda situación que, por considerar superior a un determinado grupo, conduzca a tratarlo con privilegio; o que, a la inversa, por considerarlo inferior, lo trate con hostilidad o de cualquier forma lo discrimine del goce de derechos que sí se reconocen a quienes no se consideran incursos en tal situación. La jurisprudencia de la Corte también ha indicado que en la actual etapa de la evolución del derecho internacional, el principio fundamental de igualdad y no discriminación ha ingresado en el dominio del jus cogens. Sobre él descansa el andamiaje jurídico del orden público nacional e internacional y permean todo el ordenamiento jurídico. (IACH, 2012, p. 27).

A discriminação é mais que um simples tratamento desigual que nega igual status porque a restrição a direitos se dá com base em preconceitos e estigmas baseados em traços identitários reputados inferiores. Ela conta com um fundamento discursivo de inferiorização, que é colonial e atual. $\mathrm{O}$ direito internacional dos direitos humanos tem reconhecido essa realidade e tentado construir um quadro de proteção baseado nas assimetrias produzidas por uma falsa percepção de inferioridade de determinados grupos que impede a garantia dos direitos humanos.

\section{CONSIDERAÇÕES FINAIS}

O direito internacional dos direitos humanos parte da realidade concreta da negação de direitos a pessoas e grupos que foram historicamente considerados inferiores pelas mais diversas razões. E tenta corrigir esse tratamento desvantajoso, chamado de discriminação, por meio de um vasto arcabouço normativo. Com base no

\footnotetext{
${ }^{11} \mathrm{O}$ racismo e a discriminação, especialmente a nível institucional, foram citados como sérias preocupações por vários membros da sociedade civil e representantes do governo que trabalham no âmbito da igualdade racial. O racismo permeia todas as áreas da vida, no entanto, tem sido difícil para os afro-brasileiros levantar e discutir a questão, já que muitos acadêmicos e atores nacionais e internacionais ainda subscrevem o mito da democracia racial. Isto é frequentemente usado por políticos conservadores para desacreditar as ações afirmativas e políticas e leis especiais (UN, 2014, p. 5).
} 
pressuposto de que a violação de direitos humanos é seletiva, porque atinge de forma desigual indivíduos e grupos, buscou-se analisar a causa desse processo nos discursos desumanizantes construídos ao longo da modernidadecolonial. A inferiorização de certos grupos e seres humanos segue uma lógica colonial porque além da força bruta, a dominação de uns sobre os outros necessita de discursos de legitimação. $O$ discurso segundo o qual a racionalidade instrumental é a característica essencial da humanidade tem sido útil para fundamentar crenças sobre a inferioridade daqueles que se reputam menos humanos porque não se enquadram nas exigências racionais. Como tais, os seus direitos têm se tornado meras palavras vazias: são sistematicamente violados e não há consequências graves para aqueles que se beneficiam e praticam as violações.

Ainda que a discriminação seja um ato condenável e proscrito pelo direito internacional, ela continua ocorrendo sob as mais diversas vestes e pretextos porque persite a ideia de que existem seres inferiores e descartáveis. Porque ainda persistem, nós sustentamos que há uma lógica de colonialidade - como lado obscuro da modernidade - que ainda preside os processos de violação de direitos baseados em preconceitos. Esta lógica, ao produzir discriminação, divide o mundo, cria ressentimentos, violência e injustiça.

Como principal contribuição deste estudo, é possível concluir que há discursos criadores de preconceitos e discriminação - como racismo, xenofobia, machismo e outros - e que eles estão na base da privação seletiva de direitos humanos. Via de regra, o aplicador do Direito parte da premissa da universalidade dos direitos humanos e ignora as barreiras que lhe impedem o acesso, atribuindo a todos, negros, índios e brancos, mulheres e homens, hetero e homossexuais uma mesma condição jurídica que não se verifica no mundo real, marcado em grande escala por relações assimétricas e injustas de poder calcadas em históricos discursos desumanizantes.

\title{
DEHUMANIZING DISCOURSES AND SELECTIVE VIOLATION OF HUMAN RIGHTS THROUGH THE LOGIC OF COLONIALITY
}

\begin{abstract}
This article aims to analyze the relationship between the logic of coloniality, the discourses of dehumanization that graduating humans at different scales of value and selective violation of human rights through discrimination. The study is the result of exploratory investigations conducted through literature review theoretically guided by decolonial framework. The study draws from the hypothesis according to which the violation of human rights is selective and that international human rights law aims to combat discrimination and to guarantee rights to those who are denied the full status of a human being. Based on this, the main result is to affirm that the effective protection of human rights is due to the condition of those subjects in which the rational-individualist discourse identifies the human traits while its violation is linked to discrimination suffered by those who are not are perceived as fully human. This process of deprivation results from the modern and global coloniality logic which consists of domination through dehumanizing discourses.
\end{abstract}


Keywords: human rights; coloniality; discrimination

\section{REFERÊNCIAS BIBLIOGRÁFICAS}

BUCHANAN, Allen. The heart of human rights. Oxford: Oxford University Press, 2013.

CARNEIRO, Maria Luiza Tucci. Preconceito racial em Portugal e Brasil colônia: os cristãos novos e o mito da pureza de sangue. São Paulo: Perspectiva, 2005.

CUGOANO, Ottobah. Thoughts and Sentiments on the Evil and the Wicked Traffic of the Slavery and Commerce. London, 1787.

DOUZINAS, Costas. The end of human rights. Oxford: Hart Publishing, 2000.

DUSSEL, Enrique. Eurocentrism and modernity: introduction to the Frankfurt lectures. In: BEVERLEY, John; OVIEDO, José (Org.). The postmodernism debate in Latin America. Boundary 2, Durham, v. 20, n. 3, p. 65-76, fall, 1993.

DUSSEL, Enrique. Filosofía de la Liberación. 4a ed. Bogotá: Editorial Nueva America, 1996.

FANON, Frantz. Black Skin, White Masks. Translated by Charles Lam Markmann. London: Pluto Press, 2008.

FAIRCLOUGH, Norman. Language and Power. $2^{\text {nd }}$ Edition. Harlow: Pearson Education, 2001.

FUCHS, Stephan. Against essentialism: a theory of culture and society. Cambridge, Massachusetts, and London: Harvard University Press, 2001.

GORDON, Lewis R. "Theory in Black Teleological Suspensions in Philosophy of Culture". Qui Parle: Critical Humanities and Social Sciences, Volume 18, Number 2, Spring/Summer 2010, pp. 193-214.

GROSFOGUEL, Ramón. "Para descolonizar os estudos de economia política e os estudos pós-coloniais: transmodernidade, pensamento de fronteira e colonialidade global”. Revista Crítica de Ciências Sociais, Coimbra, n. 80, p. 115-147, 2008.

INTER-AMERICAN COURT OF HUMAN RIGHTS. Case Atala Riffo and Daughters v. Chile. Judgment in february 24, 2012. Available in: http://www.corteidh.or.cr/docs/casos/articulos/seriec_239_ing.pdf. Access in $28 / 10 / 2015$.

KING Jr., Martin Luther. Letter from a Birmingham Jail Disponível em: https://www.africa.upenn.edu/Articles_Gen/Letter_Birmingham.html. Acesso em 28/10/2015.

LANDER, Edgardo. Ciências sociais: saberes coloniais e eurocêntricos. In: LANDER, Edgardo (org). A colonialidade do saber: eurocentrismo e ciências sociais. Perspectivas latino-americanas. Buenos Aires: Colección Sur Sur, CLACSO, setembro 2005. pp.21-53.

MALDONADO-TORRES, Nelson. Sobre la colonialidad del ser: contribuciones al desarrollo de un concepto. 
In: CASTRO-GÓMEZ, S.; GROSFOGUEL, R. (ed.). El giro decolonial. Reflexiones para una diversidad epistémica más allá del capitalismo global. Bogotá: Iesco-Pensar-Siglo del Hombre Editores, 2007. pp.127-167.

MIGNOLO, Walter. Who speaks for the "Human" in Human Rights? In: BARRETO, José-Manuel (ed.). Human rights from a Third World Perspective. Critique, History and International Law. Cambridge Scholars Publishing, 2013. P. 44-64.

The idea of Latin America. Oxford: Blackwell Publishing, 2008.

QUIJANO, Anibal. Colonialidade do poder, eurocentrismo e América Latina. In: LANDER, Edgardo (org). A colonialidade do saber: eurocentrismo e ciências sociais. Perspectivas latino-americanas. Buenos Aires: Colección Sur Sur, CLACSO, setembro 2005. pp.227-278.

RIOS, Roger Raupp. Direito da Antidiscriminação. Discriminação direta, indireta e ações afirmativas. Porto Alegre: Livraria do Advogado Editora, 2008.

SEPÚLVEDA, Juan Ginés de. Tratado sobre las justas causas de la guerra contra los indios. Mexico: Fondo de Cultura Económica, 1941.

SMITH, Linda Tuhiwai. Decolonizing Methodologies Research and Indigenous Peoples. 12a ed. Zed Books Ltd LONDON \& NEW YORK; University of Otago Press DUNEOIN, 2008.

UN HUMAN RIGHTS COUNCIL. Report of the Working Group of Experts on People of African Descent on its fourteenth session. A/HRC/27/68/Add.1. Sep, 2014.

WOLLSTONECRAFT, Mary. Vindicación de los derechos de la mujer. Valencia: Ediciones Catedra, 2000.

Trabalho enviado em 03 de março de 2016.

Aceito em 02 de maio de 2016. 